\title{
ПСИХОЛОГИЧЕСКОЕ СОПРОВОЖДЕНИЕ ЭКОНОМИЧЕСКОГО САМООПРЕДЕЛЕНИЯ ЛИЧНОСТИ В ПРОЦЕССЕ ЕЕ ПРОФЕССИОНАЛИЗАЦИИ В ОТРАСЛЕВОМ ВУЗЕ
}

\begin{abstract}
Аннотация. Необходимость психологического сопровождения экономического самоопределения личности в контексте ее профессионализации актуализируется в связи с усложнением и возросшей динамичностью экономической среды жизнедеятельности человека в современном мире. Взаимосвязь профессионального выбора и поиска оптимальной позиции и способа существования в системе экономических отношений, взаимоопосредованность профессионального функционирования личности и ее экономической идентичности, экономического статуса и субъективного экономического благополучия требуют рассмотрения профессионального и экономического самоопределения личности в их единстве. Предметом анализа в статье являются особенности психологического сопровождения экономического самоопределения студентов отраслевых вузов в процессе их профессионализации. Методологическую основу теоретического исследования составляют системный и субъектно-деятельностный подходы. Выводы исследования базируются на обобщении больщого массива результатов теоретических разработок и эмпирических исследований в области профессионального и экономического самоопределения личности, а также анализа теории и практики психологического сопровождения в современном образовании. Обобщение научных данных приводит к выводу о том, что профрессиональное и экономическое самоопределение личности, не смотря на их взаимообусловленность и общие "базовые» личностные детерминанты (отношения к миру, к себе, к человеческому сообществу, жизненные смыслы, ценности, притязания и т.п.), не тождественны по содержанию, что должно учитываться в методологии и практике психологического сопровождения в отраслевом образовании и при разработке соответствующих психотехнологических решений (формирующих, корректирующих, развивающих). Однако имеют место сложности, связанные, с одной стороны, с множественностью трактовок соотношения понятий «профессиональное самоопределение» и “экономическое самоопределение» (ввиду того, что длительное время эти феномены изучались независимо друг от друга или их связь анализировалась фрагментарно). С другой стороны, исследования и методические рекомендации в области психологического сопровождения учащихся 8 системе профессионального образования концентрируются преимущественно на их профессиональном и жизненном самоопределении вне взаимосвязи с экономическим самоопределением. Новизна авторского подхода к проблеме состоит в рассмотрении в качестве определяющей детерминанты экономического самоопределения личности ее экономической субъектности и в обосновании психологических условий развития экономической субъектности учащихся в контексте психологического сопровождения профессионализации личности в системе отраслевого образования.

Ключевые слова: психологическое сопровождение, экономическое самоопределение, экономическая субъектность личности, профессионализация личности, профессиональное самоопределение, развитие экономической субъектности, психологические условия, психологическое обеспечение, психотехнологии, диагностика.
\end{abstract}

Исследование выполняется в рамках проекта, поддержанного РГНФ (грант № 14-06-00249). 


\section{Психология и психотехника 8(71) • 2014}

A

ктуализация проблемы психологического сопровождения экономического самоопределения личности в контексте еe профессионализации связана с усложнением и возросшей динамичностью экономической среды жизнедеятельности человека в современном мире. Взаимообусловленность профессионального выбора, профессионального становления личности и поиска собственного места и способа существования в системе экономических отношений, собственной роли в материальном обеспечении актуальных потребностей; взаимоопосредованность профессионального функционирования личности и ее экономической идентичности, экономического статуса и субъективного экономического благополучия определяют необходимость рассмотрения процессов профессионального и экономического самоопределения личности в их единстве. Такая необходимость проявляется, в частности, в отраслевом образовании, осуществляющем подготовку по широкому спектру профессий для различных секторов экономики на фоне существенно возросших требований к конкурентоспособности этих секторов в глобальных экономических процессах. Применительно к некоторым из них (например, аграрному сектору) жизненно важной становится переориентация вузов с подготовки выпускников вузов преимущественно к наемному труду на подготовку к предпринимательской деятельности в сфере их профессионального выбора. При этом, как показывает практика, простое введение дисциплин экономического цикла или посвященных организации предпринимательской деятельности, как и реализация специальных образовательных бизнес-программ, ориентированных на «операциональную» подготовку к предпринимательской деятельности, оказываются явно недостаточными. Поскольку предполагают уже состоявшийся осознанный выбор учащегося в пользу предпринимательского варианта профессиональной карьеры и малоэффективны при отсутствии личностно-мотивационного фундамента такого выбора на фоне недостаточно выраженной экономической субъектности личности.

Экономическая субъектность личности, проявляющаяся в самодетерминации, преобразующей активности и саморегуляции личности в сфере экономических отношений, реализуется в осознанном и ответственном выборе «экономического» варианта профессиональной карьеры (в рамках наемного труда или через создание своего дела), модели трудового поведения в рамках выбранной профессии (предпочитаемом соотношении индивидуальных усилий и дохода), в «над-адаптивной» мобильности на рынке труда. Она находит выражение в осознании профессионалом (инженером, врачом, юристом и т.д.) недостаточности имеющихся материальных ресурсов для полной профессиональной самореализации в рамках наемного труда и осознанном принятии на себя ответственности за материальные возможности профессионального развития и самореализации через создание своего дела. Вместе с тем, экономическая субъектность присутствует и в феномене своеобразного «дауншифтинга» в сфере профессионального выбора, проявляющегося в осознанном отказе человека, стесненного в материальных средствах существования, от работы высокоприбыльной, но напряженной и полной стрессами, в пользу работы с низким доходом, но психологически комфортной и ненапряженной.

До последнего времени экономическая субъектность оказывалась объектом внимания преимущественно в исследованиях предпринимательства как наиболее очевидного и полного ее проявления. Это внимание акцентируется на специфической самодетерминации предпринимателя в экономической сфере, его самоорганизации, ориентации на самостоятельность и материальное самообеспечение. В отдельных работах прямо указывается на «экономическую субъектность» предпринимателя как его специфическое личностное качество ${ }^{1}$. Между тем проявление экономической субъектности личности в рамках наемного труда, в особенностях проектирования человеком своей жизненной траектории и профессиональной карьеры, в содержании профессионализации личности в процессе профессиональной подготовки остается недостаточно изученным. Необходимый для этого научный материал постепенно накапливается в рамках исследований экономического самоопределения личности и группы $^{2}$, экономического самосознания, экономической идентичности, субъективного экономиче-

\footnotetext{
Бояринцева А.В. Мотивационно-когнитивные характеристики личности молодого предпринимателя. Автореф. дисс. ... канд. психол. наук. М., 1995. 26 с.

2 Журавлёв А.Л., Купрейченко А.Б. Экономическое самоопределение: теория и эмпирические исследования. М.: Издво «Институт психологии РАН», 2007. 480 с. и др.
} 
ского статуса и благополучия ${ }^{3}$ и т.д., но на сегодняшний день этот обширный материал остается фрагментарным и неполным. Особый интерес в этой связи представляют исследования психологической готовности личности к материальному самообеспечению, в которых выявляются и изучаются условия формирования такой готовности у студентов вуза ${ }^{4}$ (поскольку ориентация на материальное самообеспечение выступает одной из имманентных характеристик экономической субъектности личности). В работах Д.А. Китовой обосновывается положение о том, что психологическая готовность человека к материальному самообеспечению связана с наличием у него специфической потребности - потребности в материальном самообеспечении - «под давлением» которой создаются материальные ресурсы для удовлетворения актуальных потребностей личности, включая ее «высшие» потребности (согласно классификации потребностей А. Маслоу). В указанном исследовании выделяются личностные характеристики, детерминирующие и определяющие эффективность деятельности, направленной на материальное самообеспечение, и предлагается основанная на них диагностическая методика (к сожалению, без полной информации о ее валидизации). В связи с проблемой развития экономической субъектности будущего профессионала подход Д.А.Китовой интересен рассмотрением «экономических» вариантов профессиональной карьеры (наемного труда или предпринимательства в сфере профессионального выбора) как способов материального самообеспечения, а также авторской психолого-педагогической программой формирования личностной готовности студентов к материальному самообеспечению.

В целом обобщение имеющихся научных данных указывает на то, что стержневое проявление экономической субъектности личности это способ жизнедеятельности человека в системе экономических отношений в целом. Проецируя известное положение Рубинштейна о двух

\footnotetext{
3 Хащенко В.А. Психология экономического благополучия. М.: ИП РАН, 2012; Diener E., Wirtz D., Tov W., Kim-Prieto C., Choi DW., Oishi S., Biswas-Diener R. New well-being measures: Short scales to assess flourishing and positive and negative feelings // Social Indicator Research. 2010. Vol. 97(2). P. 143-156.

4 Китова Д.А. Материальное самообеспечение личности в изменяющихся социально-экономических условиях. Дисс. ... докт. психол. наук. Ставрополь, 2003. 331 с.
}

способах существования человека ${ }^{5}$ на его существование в системе экономических отношений, а также апеллируя к не менее известной теории «возможностной» личности Д.А. Леонтьева ${ }^{6}$, выделяюего два режима функционирования личности (детерминированного и «самодетерминированного», проявляющегося в способности человека к причинно-необусловленному выбору, к произвольному воздействию на причинноследственные закономерности, влияющие на его жизнедеятельность), можно говорить и о двух способах жизнедеятельности индивида в системе экономических отношений. В первом случае речь идет о погруженности человека в конкретные события, ситуативные непосредственные связи и отдельные отношения при неспособности подняться над ними и занять позицию проектировщика и созидателя материальных обстоятельств собственной жизни в целом. Его функционирование в системе экономических отношений имеет преимущественно внешнюю детерминацию с ориентацией на случай, везение, изменение обстоятельств и активность других людей. Второй - «над-адаптивный» - способ проявляется в выходе человека за пределы непрерывного, преимущественно внешне детерминированного, процесса функционирования в системе экономических отношений для осмысления его в целом и принятии его под собственный контроль, в проектировании и творении материальных обстоятельств и экономических условий своего жизненного пути. Человек принимает полную ответственность за собственное материальное «состояние» и материальные условия своей жизнедеятельности, в том числе за «материальные» возможности самореализации, проектируя и созидая их, выстраивая свою жизненную траекторию с ориентацией на материальное самообеспечение. Однако этот способ жизнедеятельности предполагает более высокий уровень рефлексии (рефлексии всех аспектов жизнедеятельности в их взаимосвязях и перспективе, рефлексии себя как субъекта экономических отношений и т.д.).

В этой связи интерес представляют исследования, посвященные альтернативным моделям

\footnotetext{
Рубинштейн С.Л. Человек и мир. Проблемы общей психологии. М.: Педагогика, 1997. С. 255-285.

6 Леонтьев Д.А. Новые ориентиры понимания личности в психологии: от необходимого к возможному // Вопросы психологии. 2011. № 1. С. 3-27.
} 
профессионализации личности ${ }^{7}$, различающимся преобладанием внешней или внутренней детерминации профессионального функционирования человека: «адаптивной» модели профессионализации личности и модели «профессионального развития личности». Принципиальное различие между указанными моделями заключается в различных способах жизнедеятельности человека, проявляющихся, в том числе, и в особенностях его профессиональной деятельности и профессионально-личностного развития. Теоретически и эмпирически обосновано, что взаимопереход одной модели профессионального функционирования в другую возможен только на основе преобразования внутреннего мира личности, приводящего к принципиально новому способу ее жизнедеятельности. Вместе с тем, для нас в контексте обсуждаемой проблемы интересно то обстоятельство, что реализуемая на практике модель «профессионального развития личности», характеризующаяся максимальным проявлением субъектности профессионала (осознания им своего участия и ответственности за все, что происходит с ним в профессиональной сфере, активного способствования или противодействия внешним обстоятельствам, планирования и целеполагания профессиональной деятельности, самоизменения ради достижений целей, осмысления своей профессиональной деятельности в контексте всей своей жизни) не обязательно сочетается с высоким уровнем экономической субъектности, поскольку процессы становления профессиональной и экономической субъектности гетерохронны. Вышесказанное, в свою очередь, может ограничивать «материальные» возможности профессиональной самореализации человека или негативно сказываться на его удовлетворенности собой и жизнью в целом.

Выбор и особенности реализации способа жизнедеятельности в системе экономических отношений, как и определение своего места и оптимальной позиции в этих отношениях (трудовых, обменных, имущественных, распределительных и др.), составляют содержание и результат экономического самоопределения личности. Вместе с тем, такие содержательные составляющие экономического самоопределения, как отношение личности к экономическим благам, к источникам

Митина Л.М. Психология профессионального развития личности: теоретико-методологические проблемы // Российский научный журнал, 2010. № 1 (14). С. 57-63. богатства, к собственности, к различным видам экономической активности, а также экономическая идентичность и удовлетворенность, субъективный экономический статус и т.п., являются значимыми детерминантами профессионального выбора человека, его субъективного благополучия в сфере этого выбора.

Исследования показывают, что экономическое самоопределение личности, как психологический результат и специфическая форма активности экономического самосознания, имеет сложную личностную детерминацию, фундамент которой составляют базовые (принимаемые или формируемые самой личностью) отношения к миру и к самой себе, ее собственная система жизненных смыслов, принципов и ценностей, притязаний, ожиданий и представлений о возможностях ${ }^{8}$. Теоретически обоснована и эмпирически подтверждена определяющая роль нравственно-психологической детерминации экономического самоопределения личности ${ }^{9}$, отношения личности к праву, к себе и другим людям как его субъектам ${ }^{10}$.

Вышесказанное необходимо учитывать в современной практике психологического сопровождения студентов, при совершенствовании его методологии и создании адекватного его задачам «инструментария». Однако при этом обнаруживаются сложности, связанные с отсутствием в отечественной науке единого понимания соотношения понятий «профессиональное самоопределение» и «экономическое самоопределение» ввиду того, что длительное время эти феномены изучались не-

\footnotetext{
8 Журавлев А.Л., Купрейченко А.Б. Экономическое самоопределение: теория и эмпирические исследования. М.: Издво «Институт психологии РАН», 2007. 480 с.; Купрейченко А.Б. Нравственно-психологическая детерминация экономического самоопределения личности и группы. Автореф. дисс. ... докт. психол. наук. М., 2010. 47 с.

9 Купрейченко А.Б. Нравственно-психологическая детерминация экономического самоопределения личности и группы. Автореф. дисс. ... докт. психол. наук. М., 2010. 47 с.; Горбачева Е.И., Купрейченко А.Б. Отношение личности к деньгам: нравственные противоречия в оценках и ассоциациях // Психологический журнал. 2006. Т. 27. № 4. С. 26-37; Хащенко Т.Г., Болтунова С.В. Нравственная составляющая экономического самоопределения выпускников аграрных вузов как фактор их деловой активности. Актуальные вопросы аграрной науки и образования. Ульяновск, 2008. С. 327-330.

10 Хащенко Т.Г., Ганяк О.И. Правомерная направленность личности как детерминанта отношения российского агрария к предпринимательской деятельности // В мире научных открытий. Красноярск, 2013. № 7.1 (43). С. 278-294.
} 
зависимо друг от друга, не рассматривая их взаимосвязь и взаимообусловленность (либо эта связь анализировалась фрагментарно в границах задач конкретного исследования). Поэтому в трудах последних лет, указывающих на существование такой взаимосвязи, отсутствует единая ее трактовка. В одних публикациях профессиональное самоопределение личности рассматривается как частный аспект экономического ${ }^{11}$, в других говорится об их взаимообусловленности как имеющих свое специфическое содержание и подразумевается нетождественность «взаимоопосредованных» жизненного, экономического, профессионального и личностного самоопределения ${ }^{12}$. Одними авторами высказывается мнение о том, что при выборе стратегии экономического самообеспечения первым шагом является выбор профессии, а для этого личность предварительно должна пройти этап профессионального самоопределения ${ }^{13}$. С другой стороны, в целом ряде исследований отмечается, что современная молодежь, в отличие от предыдущих поколений, выбирает профессию с точки зрения возможности этой профессии удовлетворить «материальные» притязания выбирающего, обеспечить материальный комфорт и высокое качество жизни (то есть, профессиональное самоопределение следует за экономическим).

На фоне общего признания экономического самоопределения личности как важнейшего психологического основания ее профессионализации, взаимосвязь экономического и профессионального самоопределения изучается преимущественно на контингенте студентов экономических специальностей и направлений подготовки (или исследуется проявление этой взаимосвязи в поведении выпускников образовательных учреждений на рынке труда). Значимый в контексте обсуждаемой проблемы эмпирический материал получен в исследованиях нравственно-психологической детер-

11 Васильева Ю.Х. Экономическое самоопределение и стратегии самообеспечения молодежи // Гуманитарные научные исследования. Апрель 2012. № 4. (URL: http://human.snauka. $\mathrm{ru} / 2012 / 04 / 1044$ (дата обращения: 19.02.2014)).

12 Меренкова Л.Ю. Психологические условия развития экономического самоопределения будущих коммерсантов. Дисс. ... канд. психол. наук. Сургут, 2007. 206 с.

13 Васильева Ю.Х. Экономическое самоопределение и стратегии самообеспечения молодежи // Гуманитарные научные исследования. Апрель 2012. № 4. (URL: http://human.snauka. ru/2012/04/1044 (дата обращения: 19.02.2014)). минации экономического самоопределения студентов разной профессиональной направленности, особенностей их экономического самосознания (детерминации, структуры, динамики) ${ }^{14}$, в ряде исследований личностной детерминации отношения студентов к предпринимательскому варианту карьеры, в исследованиях некоторых особенностей экономического самоопределения представителей разных типов профессий ${ }^{15}$. Однако эмпирические данные о связи профессионального и экономического самоопределения личности пока немногочисленны и представлены преимущественно выявленными корреляциями «частных» результатов экономического самоопределения студентов вузов и выпускников с выбранной ими профессией, направлением их профессиональной подготовки.

На текущий момент, не смотря на обширный теоретический и эмпирический материал, полученный при исследовании профессионального и экономического самоопределения личности, остаются нераскрытыми многие аспекты их взаимосвязи, недостаточно изучена специфика их взаимообусловленности в различных сферах профессиональной деятельности и отдельных секторах экономики. Вышесказанное, в свою очередь, осложняет понимание содержательных и динамических характеристик профессионального и экономического самоопределения личности в процессе подготовки студентов к конкретной сфере профессиональной деятельности. Предлагаемые авторами исследований психолого-педагогические программы и рекомендации по совершенствованию психологической подготовки студентов к экономической деятельности в рыночных условиях, к предпринимательству или к наемному труду, к материальному самообеспечению, при всей их научной и прикладной ценности ориентированы в большей мере на операциональную составляющую. Кроме того, эти программы не рассматриваются как элемент системной работы в рамках психологического сопровождения профессионализации личности

14 Журавлев А.Л., Купрейченко А.Б. Экономическое самоопределение: теория и эмпирические исследования. М.: Изд-во «Институт психологии РАН», 2007. 480 с.; Купрейченко А.Б. Нравственно-психологическая детерминация экономического самоопределения личности и группы. Автореф. дисс. ... докт. психол. наук. М., 2010. 47 с.

15 Махрина Е.А. Виды и характеристики ценностно-смысловых отношений к деньгам у представителей социономических профессий. Автореф. дисс. ... канд. психол. наук. Ростов на Дону, 2006. 26 с. 
и разрабатываемый в исследовательских целях диагностический инструментарий не находит достойного применения в методических комплексах такого сопровождения.

Различные аспекты деятельности психологической службы среднего и высшего профессионального образования, функционирования центров психологической службы отражены в большом массиве публикаций. Методология и практика психологического сопровождения профессионализации личности в образовательном учреждении широко обсуждаются в психологических, акмеологических и педагогических трудах, анализируются различные модели психологического сопровождения образования и их преимущества ${ }^{16}$. Изучается зарубежный опыт, в том числе методом контент-анализа сайтов различных зарубежных университетов ${ }^{17}$. Вместе с

16 Забродин Ю.М., Пахальян В.Э. Психологическое консультирование. М.: ЭКСМО, 2010. 384 с.; Зеер Э.Ф. Психология профессионального образования: учебное пособие. М.: Изд-во МПСИ, 2003. 480 с.; Катаева Л.И. Психолого-акмеологическая служба в системе федерального и регионального управления: учебно-методическое пособие. М.: РАГС, 2005. 32 с.; Личность и профессия: психологическая поддержка и сопровождение. Учебное пособие для студентов педагогических вузов / Под ред. Л.М. Митиной. М.: Академия, 2005. 336 с.; Психологические центры: организация, содержание деятельности, документация / Под ред. С.Б. Малых. М.: Генезис, 2007. 243 с.; Особенности психологического сопровождения учебной деятельности студентов: колл. моногр. / Под науч. ред. Г.Ю. Авдиенко. СПб.: ЛГУ им. А.С. Пушкина, 2010. 116 с.; Пашкова А.П. Психолого-акмеологическое сопровождение студентов на начальном этапе планирования карьеры. Дисс. ... канд. психол. наук. Ростов-на-Дону, 2010. 183 с.; Плугарева А.В. Психологическое сопровождение развития конкурентоспособной личности студента. Дисс. ... канд. психол. наук. Пятигорск, 2008. 251 с.; Плугина М.И. Служба психологического сопровождения // Высшее образование в России. 2005. № 6. С. 124-126, Постникова М.И. и др. Психологическое сопровождение личности в условиях меняющейся социальной реальности / Под общ. ред. М.И. Постниковой. Архангельск: Поморский ун-т, 2007. 243 с.; Психологическая служба в современном образовании: рабочая книга / Под ред. И.В. Дубровиной. СПб.: Питер, 2009. 400 с.; Холмогорова А.Б. и др. Служба психологического сопровождения студентов вузов: проблемы становления, основные направления, методы и принципы работы // Вопросы психологии. 2010. № 4. С. 55-64; Щербанева Н.Г. Психологическая поддержка профессионального развития студентов педвуза средствами психологической службы. Дисс. ... канд. психол. наук. Армавир, 2003. 207 с.

17 Блохина И.А. Цели и структура психологических служб зарубежных университетов // Журнал практикующего психолога. 2004. Выпуск 10. С. 140-149; Укке Ю.В. тем, с одной стороны, термин «психологическое сопровождение», по-прежнему, сохраняет в научной литературе множественные авторские трактовки, с другой, в этих трактовках и предлагаемых моделях, как правило, экономическое самоопределение личности, не рассматривается в качестве самостоятельного объекта психологического сопровождения. Определяя для себя приоритетной целью развитие субъектности учащегося в целом, специалисты, как правило, не уделяют специального внимания, такому ее аспекту, как субъектность экономическая. Поэтому не обсуждаются методология и «инструментарий» такого сопровождения (методические диагностические комплексы, выявляющие актуальные результаты и динамику экономического самоопределения студентов, и какие-либо технологические решения: развивающие, корректирующие, формирующие).

То, что преобладающий массив теоретических разработок, эмпирических данных и методических рекомендаций в области психологического сопровождения учащихся в системе профессионального образования концентрируется преимущественно на профессиональном и жизненном самоопределении личности вне их содержательной взаимосвязи с экономическим самоопределением, обусловлено объективно исторически. Значительная часть отечественных фундаментальных разработок проблемы профессионального самоопределения и профессионального развития личности в процессе вузовской подготовки, образующих теоретико-методологическую основу современных исследований, как и накопленный ранее эмпирический материал, используемый для аргументации положений, были получены в рамках представления о профессиональном будущем студентов как профессиональной деятельности в рамках наемного труда. Это же представление, часто нерефлексируемое и не обсуждаемое авторами, сохраняется и в большей части «постсоветских» исследований (за исключением работ, посвященных подготовке к предпринимательству). Поэтому опосредованность

Психологическая служба в зарубежных вузах // Психологическая служба ВУЗа: принципы, опыт работы. Сб. научных трудов. М.: НИИВО, 1993. С. 201-212; Whiteley J.M., Burkhart M.Q., Harwey-Herman M., Whiteley R.M. Counseling and Student Development // Ann. Rev. Psychol. 1975. 26. P. $337-366$. 
профессионального самоопределения личности содержанием экономического самоопределения остается «за рамками» и, как следствие, не учитывается в достаточной мере в методологии и практике психологического сопровождения студентов вуза. Между тем, профессиональная деятельность врача как наемного работника и «частная» врачебная практика, руководство государственным или собственным медицинским учреждением предъявляют разные требования к личности так же, как и работа агронома по найму или частная практика паркового дизайнера. В динамичном и сложном мире, в котором осуществляет профессиональную деятельность современный выпускник отраслевого вуза, проектирование им жизненной траектории и профессиональной карьеры, самопроектирование профессионала, предполагают сложную внутреннюю деятельность личности, в которой процессы ее профессионального и экономического самоопределения неразрывно взаимосвязаны. И это единство процессов экономического и профессионального самоопределения должно находить свое отражение в современной практике психологического сопровождения профессионализации личности.

Из общего понимания психологического сопровождения как системы организационных, диагностических, обучающих, корректирующих и развивающих мероприятий, направленных, прежде всего, на профессионально-личностное развитие всех субъектов образовательного пространства на основе актуализации их личностного потенциала в единстве с актуализацией потенциала среды, следует, что психологическое сопровождение экономического самоопределения студентов включает не только индивидуальную и групповую работу со студентами и преподавателями, но и анализ вузовской образовательной и организационно-культурной среды (с точки зрения их благоприятности для развития экономической субъектности студентов). Каждая из этих составляющих предполагает адекватное психологическое обеспечение. Это психологическое обеспечение должно включать, прежде всего, компактные и удобные в практическом применении инструменты диагностики особенностей экономического самоопределения студентов, методики мониторинга «средовых» условий развития экономической субъектности учащихся и анализа особенностей полисубъектного взаимодействия (студент-преподаватель-психолог), содержательно связанного с экономическим самоопределением студентов. В этой связи целесообразно вспомнить, что экономическое самоопределение личности может быть отнесено сразу к трем основным классам психических явлений: процессам, состояниям (как срез процесса на определенном этапе развития), свойствам субъекта (самоопределяющаяся личность). Выделяемые специалистами содержательные (результативные и процессуальные) и формально-динамические характеристики экономического самоопределения личности ${ }^{18}$, должны быть доступны изучению при помощи соответствующего диагностического инструментария.

«Технологическая» составляющая психологического обеспечения экономического самоопределения личности в процессе ее профессионализации в вузе должна быть представлена психотехнологиями, обеспечивающими необходимые преобразования во внутреннем мире студента, следствием которых выступает «над-адаптивный» способ функционирования в системе экономических отношений. Эти технологические решения, с одной стороны, должны актуализировать и направлять рефлексивный ресурс студента на осознание связи собственного способа существования в системе экономических отношений с достижением жизненных и профессиональных целей, с другой - обеспечивать условия для формирования (коррекции, развития) у студента личностных предикторов субъектной активности в экономическом пространстве его жизнедеятельности. Вариант подобного технологического решения, эффективность которого получила экспериментальное подтверждение, успешно интегрирован нами в образовательный процесс отраслевого вуза ${ }^{19}$. Вместе с тем, на текущий момент очевидна недостаточная разработанность инструментального (диагностического и технологического) обеспечения практики психологического сопровождения экономического самоопределения личности в процессе профессионализации в вузе.

\footnotetext{
18 Журавлёв А.Л., Купрейченко А.Б. Структура и личностные детерминанты экономического самоопределения субъекта // Психологический журнал. 2008. Т. 21. № 2. С. 5-15.

19 Митина Л.М., Хащенко Т.Г. Психотехнология формирования готовности личности к предпринимательской деятельности (на материале аграрного образования) // Психология и психотехника. 2011. № 7. С. 46-55; Хащенко Т.Г. Формирование предпринимательской направленности личности у студентов аграрных вузов // European Social Science Journal. 2013. № 8-1. C. 161-170.
} 


\section{Психология и психотехника 8(71) • 2014}

Подводя итог, можно сделать следующие выводы:

1. Профессиональное и экономическое самоопределение личности, несмотря на их тесную взаимосвязь и взаимоопосредованность, а также общность их фундаментальных личностных детерминант (базовых отношений личности к миру и к себе, жизненных смыслов личности и т.д.) не тождественны и имеют собственное специфическое содержание, которое должно «охватываться» психологическим сопровождением образовательного процесса в вузе.

2. Системообразующей составляющей психологического сопровождения экономического самоопределения личности выступает развитие ее экономической субъектности. Необходимыми психологическими условиями развития экономической субъектности учащихся являются рост их экономического самосознания и формирование личностного фундамента экономической субъектности (личностных предикторов субъектной активности в сфере экономических отношений, определяющих экономические, социальные, нравственноэтические и иные следствия этой активности для личности и общества). Эти условия в целом обеспечиваются в рамках гуманистической образовательной парадигмы в развивающей образовательной среде (интегративным критерием качества которой выступает способность обеспечить всем субъектам образовательного процесса систему возможностей для эффективного личностного саморазвития $\left.{ }^{20}\right)$. Вместе с тем, принимая во внимание возможность асинхронности и противоречивости становления субъектности профессионала и экономической субъектности личности в период обучения студентов в вузе, желательно интегрирование в деятельность психологических служб отраслевых вузов специальных программ психологического сопровождения. Эти программы, включающие, как минимум, три направления работы (групповую и индивидуальную работу со студентами, работу с преподавателями и работу по оптимизации вузовской среды) предполагают наличие соответствующего психологического обеспечения.

20 Панов В.И. Психодидактика образовательных систем: теория и практика. СПб.: Питер, 2007. 352 с. и др.
3. Психологическое обеспечение экономического самоопределения личности в процессе профессионализации в вузе должно включать «специфический» диагностический инструментарий, специальные методические комплексы, выявляющие содержательные и формально-динамические характеристики экономического самоопределения учащихся, его актуальные результаты и их динамику. В такие методические комплексы может войти диагностический инструментарий, разработанный для решения конкретных исследовательских задач ${ }^{21}$, однако актуальным является создание специализированного банка диагностических методик, удобных в практическом применении и отвечающих задачам психологического сопровождения экономического самоопределения личности в процессе профессионализации. Технологический «блок» психологического обеспечения экономического самоопределения студентов должен быть представлен технологическими решениями, основанными на актуализации рефлексивного ресурса студента в направлении максимально полного осознания связи собственного способа жизнедеятельности в системе экономических отношений с достижением жизненных и профессиональных целей, осознания себя как субъекта экономических отношений, собственных психологических ресурсов и мотивации собственной экономической активности, спектра возможностей самореализации в различных формах экономической активности в сфере профессионального выбора.

21 Вяткин А.П. Исследование самоопределения личности в экономических ролях // Вестник Новосибирского государственного университета. Серия: Психология, 2007. Т. 1. № 1. С. 44-51; Горбачева Е.И., Купрейченко А.Б. Отношение личности к деньгам: нравственные противоречия в оценках и ассоциациях // Психологический журнал. 2006. Т. 27. № 4. С. 26-37; Журавлев А.Л., Купрейченко А.Б. Экономическое самоопределение: теория и эмпирические исследования. М.: Институт психологии РАН, 2007. 480 с.; Хащенко В.А. Субъективное экономическое благополучие и его измерение: построение опросника и его валидизация // Экспериментальная психология. 2011. № 1. С. 106127; Карнышев А.Д., Бурменко Т.Д., Иванова Е.А. Экономическая психология собственности. Иркутск: БГУЭП, 2006. 346 с. и др. 